\title{
Characterization of Isogrid Structure in GFRP
}

\author{
Costanzo Bellini, Luca Sorrentino \\ University of Cassino and Southern Lazio, Department of Civil and Mechanical Engineering, Italy \\ costanzo.bellini@unicas.it, http://orcid.org/0000-0003-4804-6588 \\ luca.sorrentino@unicas.it, bttp:/ /orcid.org/0000-0002-5278-7357
}

\begin{abstract}
Lightening parts, maintaining also a high strength, is a request of the transport industry. Isogrid structures represent one of the best answer to face these issues, especially if composite materials are considered for their production. However, the fabrication of these structures is very complex, as defects can arise that cause the part discarding or the part failure during service. The properties of the fabricated structure depend on some process characteristics, as the forming technology, the process parameters and the tools that have to be wisely designed. Isogrid structures are characterized by the ribs, so the mould shape must be carefully planned. In fact, a common defect that usually occurs is a scarce compaction of the ribs, which involves porosity and low mechanical strength.

In this paper, the manufacturing process peculiarities for GFRP (Glass Fibre Reinforced Polymer) isogrid structures were defined, then both the mould and the parts were produced. Structural tests were carried out on these structures in order to validate the process design methodology, paying particular attention to the structural properties of the ribs, as the compaction degree and the interlaminar shear strength. Finally, some actions were undertaken to avoid the problems found in the first production run.
\end{abstract}

KEYWORDS. Isogrid structures; Composite materials; Curing; Interlaminar shear strength; Complex shape.

\section{OPEN ACCESS}

Citation: Bellini, C. and Sorrentino, L., Characterization of Isogrid Structures in GFRP Frattura ed Integrità Strutturale, 46 (2018) 319-331.

Received: 03.08 .2018

Accepted: 07.09 .2018

Published: 01.10.2018

Copyright: (C) 2018 This is an open access article under the terms of the CC-BY 4.0, which permits unrestricted use, distribution, and reproduction in any medium, provided

the original author and source are credited.

\section{INTRODUCTION}

$\mathrm{T}$ he most advanced engineering products demand the application of advanced materials together with innovative design concepts. The increasingly stringent environmental regulations require that in the transport sector the fuel consumption and, consequently, the emissions must be reduced to decrease the air pollution. Among popular solutions, this objective can be achieved by reducing the weight of the parts, though without affecting their structural resistance. 
In a work of Frulloni et al. [1], the design and manufacturing of isogrid structures made of composite materials is the best answer to this demanding task as composite materials present high resistance/weight ratio, while isogrid structures provide excellent performances for thin-walled components subjected to buckling failure; it is not without reason that this kind of structure are increasingly used in aeronautical and aerospace applications. These structures are composed by an isogrid lattice, formed by helical and circumferential ribs, surrounded by a thin skin: in such manner, the final product consists in a lightweight structure characterized by high mechanical performances. In the past years, there have been a lot of examples of aerospace and aeronautic parts conceived following this philosophy: fuselage structures, payload adapters and inter-stage structures have been produced resorting to large scale lattice cylinders; moreover, they have been implemented for Skylab Orbital Workshop module, Delta carriers and fuselage structures by Boeing, as reported by Dawood et al., Totaro and Zheng et al. [2-4].

Several studies in the literature deal with the mechanical performance of lattice structures. The buckling failure modes of lattice structures made of composite material were studied by Totaro [5-6]. In particular, he applied analytical models on both triangular and hexagonal cells system, after those models were experimentally verified on a curved lattice panel with an axial compressive load by Totaro et al. [7]. Lattice structures failure was predicted by other researchers too, that prepared several models. The higher mechanical performance of lattice structures in comparison with sandwich or stringer ones was proved in different work by Sun et al., Vasiliev et al. and Zheng et al. [8-11]. A FEM model was applied by Sui et al. on a one-dimensional lattice truss composite structure to analyse the compression failure mechanism, finding out that shorter truss fail for strut fracture, while the longer one for global buckling [12]. Instead, the characteristic failure mode of lattice-core sandwich structures was local buckling and delamination, as stated by Fan et al. [13]. According to Wang and Abdalla, lattice composite structures have higher damage tolerance characteristics [14].

The fabrication of isogrid structures made of composite material is very complex, as defects can arise that cause the part discarding or the part failure during service [15]. The forming technology, the necessary equipment and the process parameters must be determined with care, since they strongly affect the quality of the produced parts [16]. In particular, the mould shape has to be carefully designed since the part presents a complex geometry, due to the presence of ribs. In fact, a common defect that usually occurs is a bad compaction of the ribs, which involves porosity and low mechanical strength. An issue that commonly rise during manufacturing of isogrid structures is connected to the rib intersection, where the fibres cross-over. In fact, in these nodes there is three time the amount of fibre than in the other zones, giving rise to excessive build-up, that causes compaction problems and stress concentration points, as indicated by Young [17]. In these points the stress level can reach too high value and provoke a premature structural failure. Moreover, the nonuniformly distributed load caused by build-up can give rise to cure induced deformation of the lattice structure, because of CTE (Coefficient of Thermal Expansion) mismatch between fibres and resin [18]. A simple method to lessen the build-up and, consequently, its negative effects is represented by fibres offsetting: a few millimetres shift of the circumferential ribs is sufficient to reduce the overlapping from three plies to two. On the contrary, with this method small empty spaces are created at the centre of the nodes, which must be filled with resin during the cure process, as asserted by Kim [19].

The target of this research concerns the manufacturing of isogrid following an innovative process design methodology, that was verified through experimental structural tests on the produced parts. In particular, the mould groove geometry was defined in order to avoid part getting stuck in the mould and to obtain the right compaction degree. Then, different experimental tests were carried out to determine the quality of the produced structures and so the suitability of the designed mould. Finally, some actions were undertaken to avoid the problems rose in the first production run, on the basis of the quality tests.

\section{MATERIALS AND METHODS}

$\mathrm{T}$ he rib geometry was designed according to the Vasiliev's theory in a previous work by Sorrentino et al. [20], in which a cylindrical isogrid structure was studied. In particular, the rib thickness was defined equal to $2 \mathrm{~mm}$ and the rib width to $5 \mathrm{~mm}$; other geometrical parameters of the lattice structure were: triangle width equal to $94.25 \mathrm{~mm}$, triangle height to $83.33 \mathrm{~mm}$, helical angle to $60.51^{\circ}$, structure diameter to $300 \mathrm{~mm}$ and structure height to $338 \mathrm{~mm}$. However, only a sector equal to one fifth of the structure was considered for the purpose of this work, as visible in Fig. 1. As a first approach for the realization of the structure, after having designed the mould and chosen the stratification sequence, the lattice structure alone was produced, without the skin. This procedure made it possible to optimize, as further described below, the production process as well as the isogrid structure itself. If the part had been made directly with the skin it would not have been possible to analyse the dimensions and the real compaction of the ribs, which, as can 
be guessed, turned out to be the critical element of the structure. A unidirectional prepreg tape made of glass fibre and epoxy resin, whose parameters of interest are reported in Table 1, was chosen as material for this work.

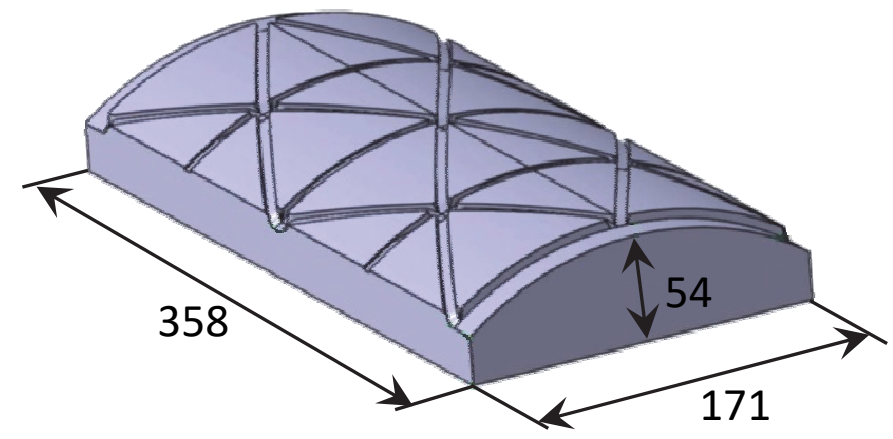

Figure 1: Mould dimensions for one fifth of the structure.

\begin{tabular}{lc}
\hline \multicolumn{1}{c}{ Property } & Value \\
Resin weight content & $33 \%$ \\
Composite density & $1850 \mathrm{~kg} / \mathrm{m} 3$ \\
Fibre weight & $0.66 \mathrm{~g} / \mathrm{m}$ \\
\hline
\end{tabular}

Table 1: Material properties.

\section{Mould design}

For the design of the mould required for the manufacturing of the isogrid structure, the manufacturing technology was considered in addition to the geometry of the structure, because the technology inevitably determined a geometric/dimensional variation of the ribs compared to the drawn ones. Therefore, the design phases of the mould and the subsequent optimization step proved to be fundamental for obtaining the appropriate quality of the produced parts; the mould, in fact, must guarantee the dimensions, the compaction and the surface finish of the final piece.

A well-defined geometry and dimensions were assigned to the mould channels in order to guarantee the deposition of the composite material roving and to facilitate as much as possible the compaction and the subsequent extraction. The groove depth was chosen considering a uniform compaction and a rib thickness of $2 \mathrm{~mm}$; therefore, the channel depth between two intersection point was $2 \mathrm{~mm}$, while in the intersection point it was $6 \mathrm{~mm}$, that is three times the thickness of the single rib. From a geometrical point of view, the groove bottom conceived in that manner was concave, therefore it had to be managed appropriately in order to reduce to a minimum the problems of compaction due to the fibre bridging; this means ensuring a smooth transition between these two thicknesses $(2$ and $6 \mathrm{~mm}$ ). In this sense, the two chord points where the tape detached from the deposition surface were taken as reference; in particular, a distance between these two points of about $50 \mathrm{~mm}$ was chosen, as reported in Fig. 2. In this zone the channel thickness passed from $2 \mathrm{~mm}$ to $6 \mathrm{~mm}$ (in the intersection centre) and then returned to $2 \mathrm{~mm}$. Operatively, this was achieved by a sweep cutting operation with a rectangular cutting profile guided by two spline curves, as visible in Fig. 3.

A concave surface with a negative curvature was generated through this method, so an auxiliary compaction system, capable of making the fibres adhere to the groove surface during the material deposition, was required for managing the issues raised by surface geometry. In order to overcome this question, an innovative solution was studied which delegated this task to the deposition of the circumferential ribs. For this reason, the thickness variation of the circumferential grooves was designed taking into account this purpose. The circumferential ribs also presented a depth variation from 2 $\mathrm{mm}$ to $6 \mathrm{~mm}$ and, taking into account their role of compaction system, to create a zero curvature surface was decided, as visible from Fig. 4. In this way, the compaction of the helical spirals was facilitated since the first fibre layer.

\section{Mould production and preparation}

A block of epoxy resin was machined for the production of the mould for the lattice structure. This material was chosen since it had a coefficient of thermal expansion compatible with that of the composite material and it was convenient for the purpose of this experimental campaign. As concern the machining sequence, the dimensions of the raw block were 
defined on the mould drawing. As reported in Fig. 5a, the first machining phase, precisely that of rough milling, was done with a $20 \mathrm{~mm}$ diameter cylindrical tool; in this way the rough shape of the mould was obtained, without the groove for rib stratification and with a surface still to be finished. For the second machining phase, that consisted in the surface finishing, a tool change was necessary, since a ball nose tool with a diameter of $10 \mathrm{~mm}$ was used, as visible in Fig. 5b.

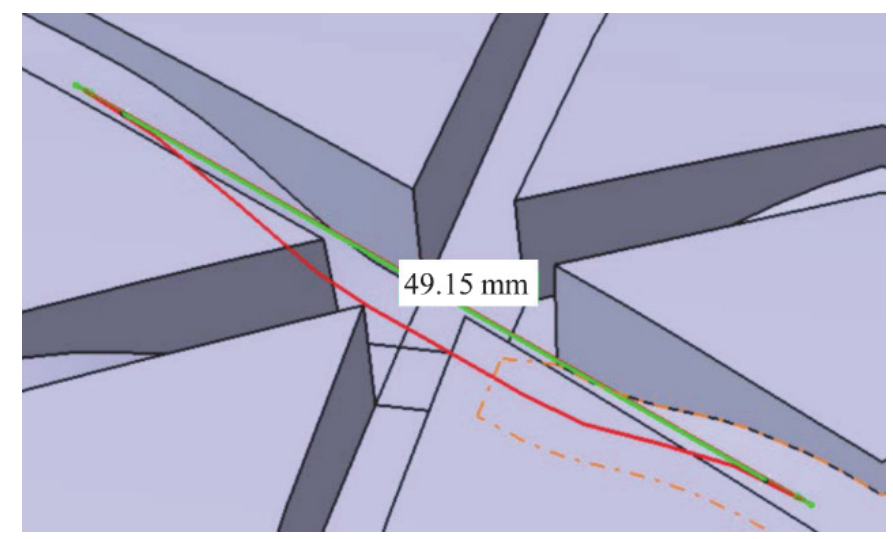

Figure 2: Length of the thickness variation zone.

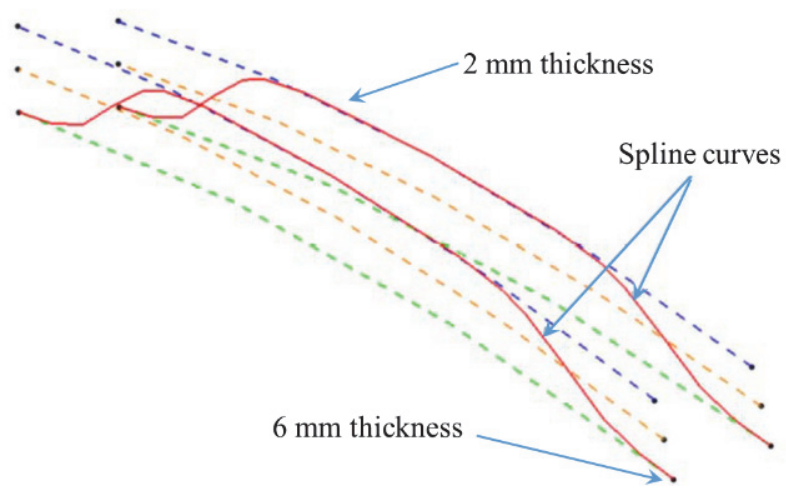

Figure 3: Spline curves for groove intersections.

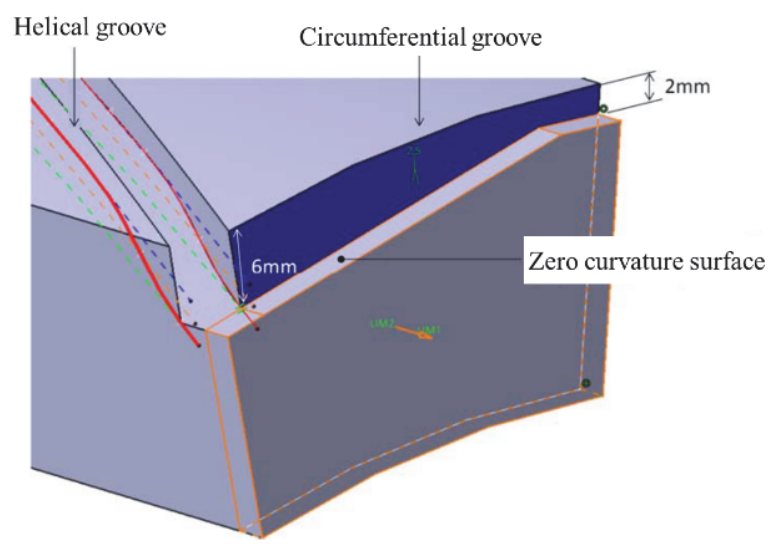

Figure 4: Circumferential groove depth variation following a plane surface.

The third machining phase, reported in Fig. $5 \mathrm{c}$, consisted in the milling of the stratification groove, made with a $5 \mathrm{~mm}$ cylindrical tool to obtain the groove width as defined in the design. These grooves also had a variable depth for the reasons extensively described above. At first the right-handed and left-handed helical grooves were machined and then the circumferential ones. For each groove there was a constant feed speed, changing only the $\mathrm{z}$-axis in the points of interest, 
or near the groove intersection. In the fourth and last machining phase, visible in Fig. $5 \mathrm{~d}$, a chamfer of $0.3 \mathrm{~mm}$ and $45^{\circ}$ was milled on both side of each groove.

The mould surface was treated before the stratification was carried out in order to make it unaffected by the dimensional variations that may occur during the cure process of prepreg. Once the correspondence between the CAD model and the produced mould was verified, a size was spread on the mould to fill the surface porosity, then a release agent was put to avoid part sticking at the end of the process; a layer of liquid wax was added, which was accurately laid down on the whole mould to make it still less porous.
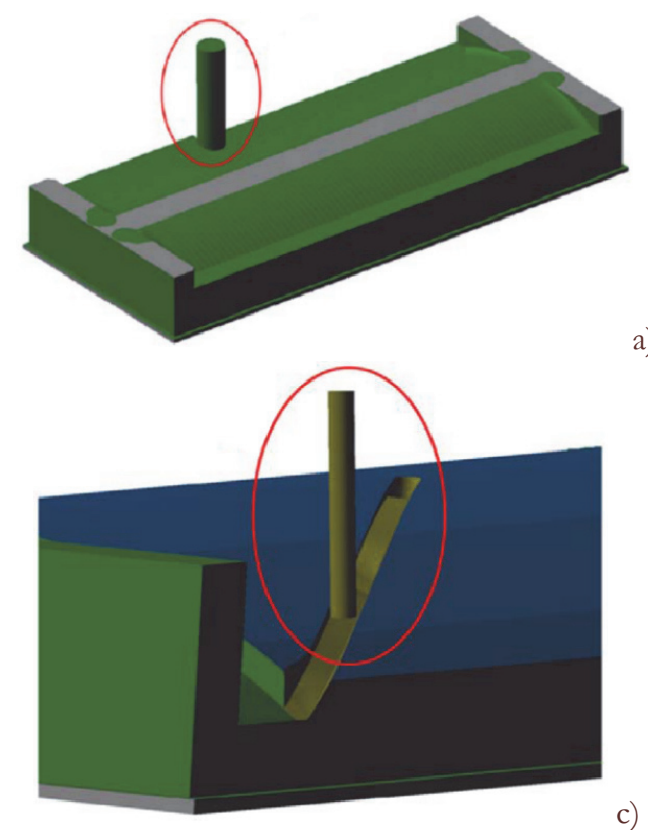

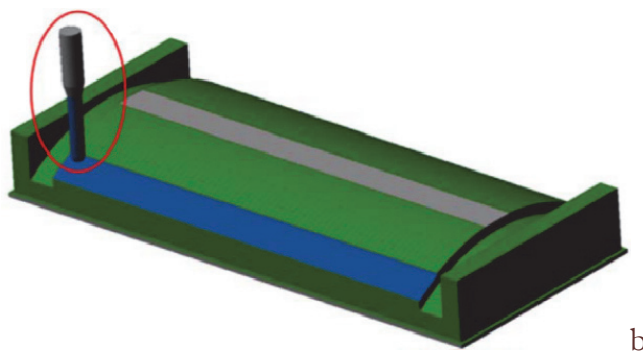

b)

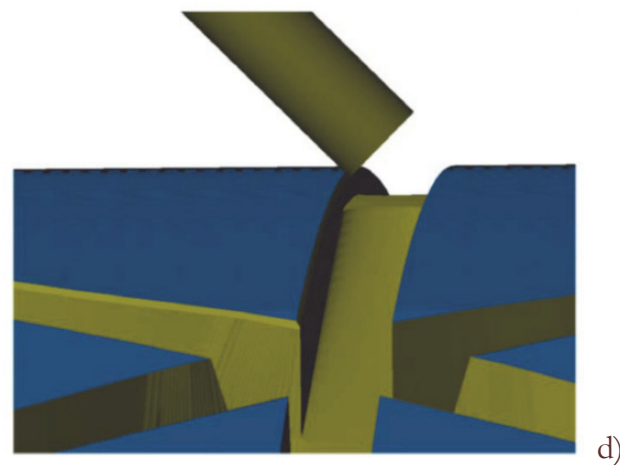

d)

Figure 5: Machining phases to produce the mould: a) cylindrical surface rough milling; b) cylindrical surface finishing; c) groove milling; d) chamfer milling.

\section{Design of tape stratification plan}

For the manufacturing of the lattice structure, to follow the grooves machined on the mould surface was necessary, stratifying the tape on the mould; for this operation it had to be taken into account the fact that the helical ribs had a radial thrust lower than the circumferential ones, therefore the stratification plan provided a first step in which all the helical ribs were stratified and then the circumferential ones; this sequence was executed for each one of the calculated layers of composite tape. The first step consisted in calculating the number of layers to be laid down to obtain the right structure dimensions, that were a rib thickness of $2 \mathrm{~mm}$ and a width of $5 \mathrm{~mm}$. Starting from the properties of the material used, the number of tape layers to be considered was calculated as described in the following. First of all, the weight per metre of the prepreg tape $\mathrm{P}_{\mathrm{C}}$ was determined from the fibre weight per metre $\mathrm{P}_{\mathrm{F}}$ and the resin weight content $\mathrm{W}_{\mathrm{R}}$ as:

$$
P_{C}=\frac{P_{F}}{1-W_{R}}
$$

The volume of a one millimetre of the rib $\mathrm{V}_{\text {rib }}$ was calculated from rib width and thickness, indicated with $\mathrm{w}_{\text {rib }}$ and $\mathrm{t}_{\text {rib}}$, respectively, according to the following relation:

$$
V_{r i b}=w_{r i b} * t_{r i b} * 1.04
$$

The weight of a one millimetre of the rib $\mathrm{P}_{\text {rib }}$ was calculated multiplying $\mathrm{V}_{\text {rib }}$ for the composite density @c by:

$$
P_{r i b}=V_{r i b} * \rho_{C}
$$


Finally, the number of tape layers $\mathrm{N}_{\mathrm{s}}$ was determined as:

$$
N_{S}=\frac{P_{r i b}}{P_{C}}
$$

Using the abovementioned relations and the material properties reported in Tab. 1, a Ns equal to 20 was fixed for the structure under investigation. To determine the tape stratification sequence, a first one is that shown in the following. Considering the mould portion placed on a two-dimensional plane and numbering all the starting points trajectories as reported in Fig. 6, a first sequence is described in Tab. 2. To better clarify the meaning of this table, some sequence steps will be explained in the following; for example, the first step describes the first helical trajectory to be executed, from point 0 up to point 6 , to lay down the tape in the groove, above the mould. The second step indicates the return trajectory of the tape, which adhered to the rear of the mould from point 6 to 8; for this reason, it is defined as "below". This choice was necessary to ensure continuity of tension and trajectory to the tape. Following the proposed sequence consisting of 18 step, all the helical ribs were stratified at first and then the circumferential ones were added, thus ensuring the adhesion of the tape on the bottom of the grooves to guarantee an even consolidation in the intersection points.

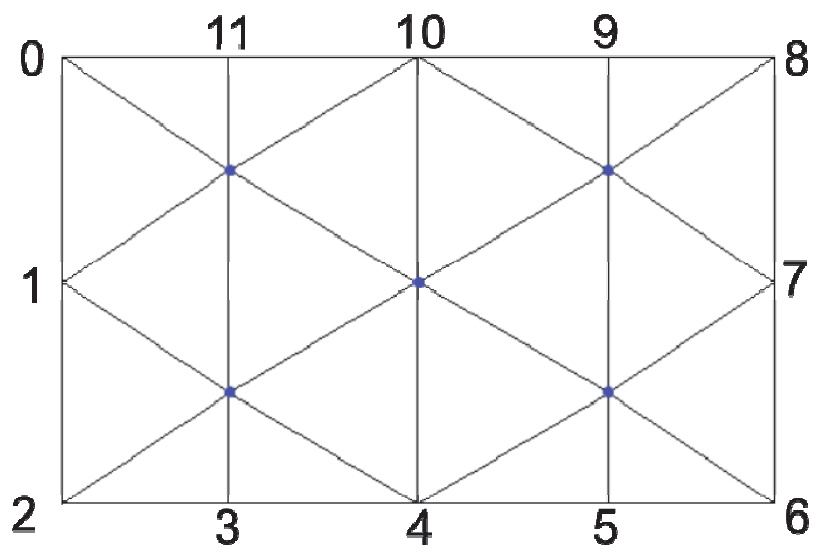

Figure 6: First stratification sequence scheme.

\begin{tabular}{ccccccccc}
\hline Step & Trajectory & Position & Step & Trajectory & Position & Step & Trajectory & Position \\
1 & $0-6$ & Above & 7 & $10-7$ & Above & 13 & $10-4$ & Above \\
2 & $6-8$ & Below & 8 & $7-6-8-7$ & Below & 14 & $4-9$ & Below \\
3 & $8-2$ & Above & 9 & $7-4$ & Above & 15 & $9-5$ & Above \\
4 & $2-1$ & Below & 10 & $4-10$ & Below & 16 & $5-11$ & Below \\
5 & $1-4$ & Above & 11 & $10-1$ & Above & 17 & $11-3$ & Above \\
6 & $4-10$ & Below & 12 & $1-2-10$ & Below & 18 & $3-0$ & Below \\
\hline
\end{tabular}

Table 2: First stratification sequence.

\section{Manufacturing of lattice structure}

After the machining and the surface treatment of the mould, the GFRP tape was deposited in the mould grooves. For the ribs deposition, the mould was mounted on a turntable, by using a special equipment, and the prepreg tape was laid down by hand in the mould grooves following the sequence described in the previous paragraph. The limits and difficulties of a manual deposition were those of not being able to obtain a high repeatability. Therefore, problems such as having a constant tape tensioning, being able to have perfectly overlapping layers and avoiding neck-in and twist of the tape are 
typical issues that can be solved only with a robotic filament winding system, as that proposed by Sorrentino et al. [21]. Nevertheless, a satisfactory stratification quality was reached, even if the deposition operation lasted about 3 hours, that was a quite long time and it justify the implementation of an automatic system.

At the end of the stratification process, a debulking phase, that is a pre-compacting action suitable to obtain less porosity, was carried out by vacuum bagging before the polymerization process. In this phase the stratified tape in the mould was compacted with a vacuum of -0.8 bar to make the tape adhere as much as possible to the bottom of the groove, thus increasing material consolidation, surface finish and structural solidity. For executing the debulking operation, to prepare a vacuum bag was necessary, similar to the one required by the cure process. First of all, the mould with the laid down material was wrapped with a release film to prevent it from sticking to the other ancillaries. Subsequently a layer of breather cloth was added, which was a transpiring material allowing a better distribution of vacuum on the mould surface and, consequently, increasing the homogeneity of the compaction. Finally, the vacuum bagging film, in plastic material, was deposited on the breather cloth, completing the preparation for debulking. A valve, which was subsequently connected to a vacuum pump by means of a tube, was inserted in this last film to create the vacuum. After the compaction phase, in which the component remained for a period equal to about 4 hours, there was the polymerization phase. For the cure process, the part was heated in the autoclave for 5 hours, at a temperature of $130{ }^{\circ} \mathrm{C}$. A total of 5 structures were produced for the experimental tests.

\section{Analysis of the structure quality}

At the end of the curing process, some experimental tests were made on the produced parts. These tests were carried out to analyse the physical and the structural strength characteristics of the composite in an experimental manner. In particular, after a preliminary visual inspection, a chemical test and a mechanical one were carried out: the former was the calcination test and the latter was the interlaminar shear strength test.

The calcination test is suitable to determine the resin content in the part after polymerization, to understand how it is distributed and so to have an index on the areas with greater compaction. The specimens were extracted from those areas that appeared most interesting for this test, both in the intersection point and on a single rib. As visible in Fig. 7, six zones were highlighted from which the six specimens were respectively named: A1, A2, A3, A4, A5 and A6. Once the six specimens were extracted from the structure, the test consisted of a first phase in which the dry specimens were weighed, then they were weighted in distilled water, using a high precision balance for both operations. After being weighed, the specimens were placed in the oven at $580{ }^{\circ} \mathrm{C}$ for 2 hours, in this way the resin was pyrolysed. The hot specimens were then placed in a dryer to further promote the resin elimination, leaving the fibres unaltered. The dryer presented dehumidification salts at its base and a valve for the vapours emission in the upper end. Therefore, the so obtained specimens made of only glass fibres were weighed again. From the obtained data it was possible to calculate the resin and fibre content in terms of weight and volume percentage as well as the density and percentage of voids present in the specimens.

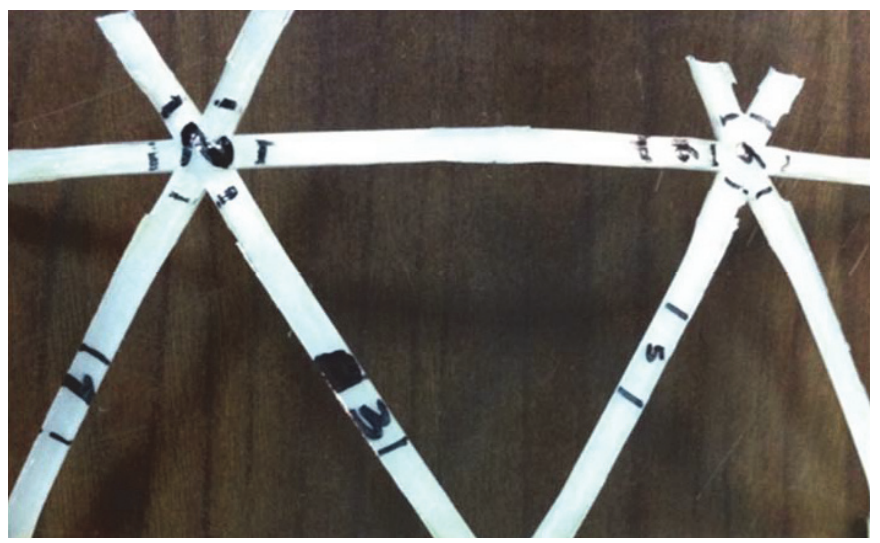

Figure 7: Specimens selection for the calcination test.

One of the better way to determine the quality of the gluing between the composite layers is the interlaminar shear strength test, carried out according to ASTM D2344. It was carried out by performing a bending test with a ratio between the supports span length and the specimen thickness equal to 4. As observable in Fig. 8, the specimens were taken from the most linear areas. The test specifications state that the specimen length must be six times the specimen thickness. 


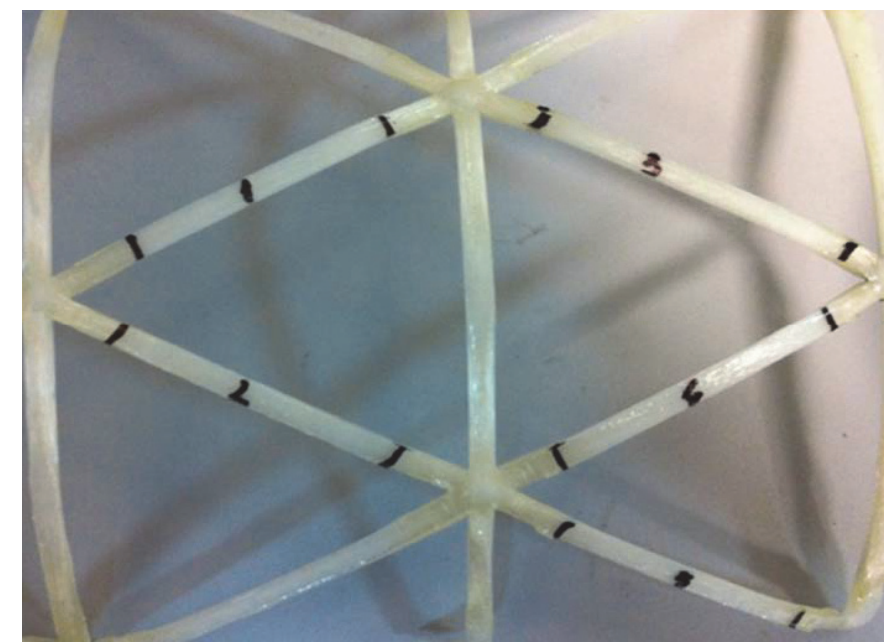

Figure 8: Specimens selection for the interlaminar shear strength test.

\section{RESULTS}

A

$t$ the end of the cure process, each lattice structure was extracted from the mould and a visual inspection was performed on the part as preliminary quality test. It was found that there were some points more involved for the tape inversion phase, in particular in the point 10 and 4 of Fig. 6 . This created during the stratification phase a greater difficulty in depositing the tape, with the eventuality of neck-in or twist of the tape. Furthermore, the designed stratification sequence foresaw no trajectories to cover the head and base circumferences; as a consequence, the intersection points along these circumferences presented some issues, as shown in Fig. 9.

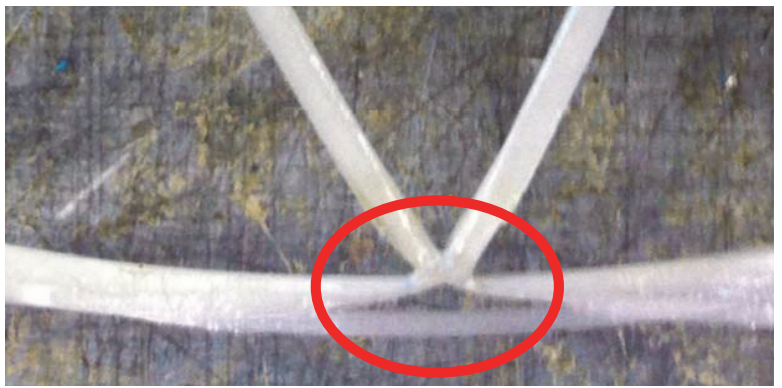

Figure 9: Defect due to lack of circumferential head trajectory.

Analysing the produced structures, it was found that the tape had not undergone a homogeneous compaction; in particular, it varied in the proximity of the intersection point, where two helical trajectories intersected a circumferential one; the calculation of the groove depth in those points was made considering a triple stratification in the intersection, and therefore it had a triple depth than the other parts of the grooves. That is, a depth of $2 \mathrm{~mm}$ was considered in the zones with a single rib, while a maximum depth of $6 \mathrm{~mm}$ was adopted for those points where there was the intersection of the three ribs. After the demoulding of the lattice structure from the curing tool, the thickness of the ribs was measured by means of a digital calliper: the thickness of a single ribs was found equal to $2 \mathrm{~mm}$, while in the intersection zone the measured thickness was $4.3 \mathrm{~mm}$. Moreover, a visual analysis showed that the grooves tracts with variable depth were too long, that is the shift from $2 \mathrm{~mm}$ to $6 \mathrm{~mm}$ takes place in a too gradual manner. In fact, the tests showed a lack of compaction with a large displacement of the fibres in the radial direction and towards the inside of the groove, with a noticeable rib hollow in those areas.

After the preliminary quality tests, the calcination tests were carried out for acquiring further information on the material compaction level in the different areas of the mould grooves. The results of these tests, that are reported in the Table 3, showed that the resin had a higher volumetric percentage in some parts of the structure than in others. Such a result could be expected but not to the extent that it occurred; in fact, according to the prepreg characteristics, the nominal resin 
contents differed considerably from those detected by experimental tests. The reason for this discrepancy was partly due to the particular piece geometry and partly to the fact that the mould grooves presented different depths, that created areas with greater compaction than others. With regard to the interlaminar shear strength tests, the relevant results are shown in the Table 4.

\begin{tabular}{ccccccccccc}
\hline \multirow{2}{*}{ Specimen } & \multicolumn{3}{c}{ Resin content [\%] } & \multicolumn{3}{c}{ Fibre content [\%] } & \multicolumn{3}{c}{ Void content [\%] } \\
& Average & St. Dev. & CoV & Average & St. Dev. & CoV & Average & St. Dev. & CoV\% \\
\hline 1 & 39.24 & 1.23 & $3.13 \%$ & 59.13 & 1.38 & $2.34 \%$ & 1.63 & 0.04 & $2.45 \%$ \\
2 & 45.47 & 1.95 & $4.29 \%$ & 38.66 & 1.68 & $4.34 \%$ & 15.87 & 0.73 & $4.58 \%$ \\
3 & 35.73 & 1.18 & $3.30 \%$ & 59.28 & 1.20 & $2.02 \%$ & 4.99 & 0.13 & $2.57 \%$ \\
4 & 41.45 & 1.83 & $4.41 \%$ & 46.54 & 1.83 & $3.93 \%$ & 12.01 & 0.60 & $4.98 \%$ \\
5 & 36.81 & 1.21 & $3.29 \%$ & 59.25 & 1.43 & $2.42 \%$ & 3.94 & 0.09 & $2.36 \%$ \\
6 & 48.86 & 2.24 & $4.58 \%$ & 40.30 & 1.99 & $4.94 \%$ & 10.84 & 0.50 & $4.63 \%$ \\
\hline
\end{tabular}

Table 3: Calcination test results.

\begin{tabular}{cccc}
\hline Specimen & $\begin{array}{c}\text { Average } \\
{[\mathrm{MPa}]}\end{array}$ & $\begin{array}{c}\text { St. } \\
\text { Dev. }\end{array}$ & $\mathrm{CoV}$ \\
1 & 54 & 14.4 & $26.69 \%$ \\
2 & 67 & 11.4 & $17.07 \%$ \\
3 & 66 & 18.1 & $27.42 \%$ \\
4 & 65 & 16.1 & $24.69 \%$ \\
5 & 66 & 12.7 & $19.18 \%$ \\
\hline
\end{tabular}

Table 4: Interlaminar shear strength test results.

As concerns the interlaminar shear strength, the values obtained in the areas far from the intersection points fall within the specifications of the considered material (ILLS>50 MPa), so the designed manufacturing methodology can be considered suitable for lattice structure production. However, in the intersection points the rib thickness measurement and the calcination test found some differences in terms of rib thickness between the nominal structure and the produced one, which were due to the fact that the prepreg resin underwent irregular transactions during the curing phase, filling more some areas rather than others. Therefore, some improvements must be implemented in the mould design to warrant the attainment of high quality standards in all the areas of the lattice structure.

\section{Preliminary process design optimization}

The isogrid structure produced with a mould designed according to the abovementioned consideration presented some issue; therefore, some improvements in the mould design and in the stratification sequence were necessary to obtain high quality parts.

First of all, in order to avoid the separation of the fibre bundles in the head areas reported in Fig. 9, an optimized stratification sequence was defined taking into account the described problems; the new sequence is shown in Table 5 . In this case it is observed that, by slightly changing the stratification philosophy previously adopted and laying down the helical trajectories at first and then the circumferential ones, there was a better distribution of the return trajectories below the mould. The result of this optimization operation can be seen from the comparison between the return trajectories obtained with the first sequence, visible in Fig. 10a, and those obtained from the optimized one, reported in Fig. 10b. Therefore, the problem related to the accumulation of tape in certain particular points was solved with the optimized sequence, thus making the changes of deposition directions less critical without the risk of twist and neck-in of the 
prepreg. Moreover, two head and base trajectories were added in order to obtain a homogeneous stratification in these two zones. It is evident that the optimized stratification turned out to be more advantageous than the first one.

\begin{tabular}{ccccccccc}
\hline Step & Trajectory & Position & Step & Trajectory & Position & Step & Trajectory & Position \\
1 & $1-4$ & Above & 8 & $1-8$ & Below & 15 & $5-10$ & Below \\
2 & $4-0$ & Below & 9 & $8-2$ & Above & 16 & $10-4$ & Above \\
3 & $0-6$ & Above & 10 & $2-7$ & Below & 17 & $4-11$ & Below \\
4 & $6-10$ & Below & 11 & $7-7$ & Head & 18 & $11-3$ & Above \\
5 & $10-7$ & Above & 12 & $7-4$ & Above & 19 & $3-1$ & Below \\
6 & $7-10$ & Below & 13 & $4-9$ & Below & 20 & $1-1$ & Base \\
7 & $10-1$ & Above & 14 & $9-5$ & Above & & & \\
\hline
\end{tabular}

Table 5: Optimal stratification sequence.
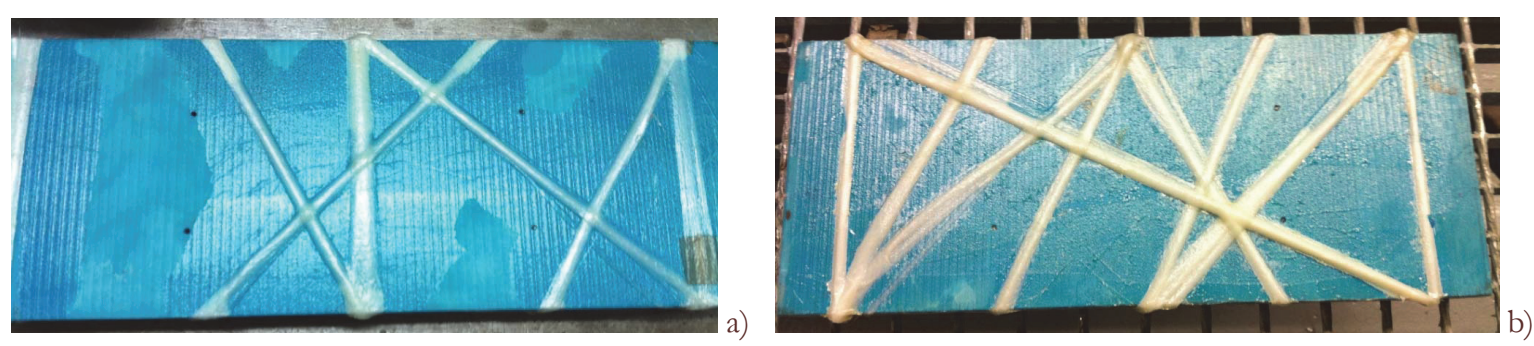

Figure 9: Return trajectories below the mould: a) first stratification sequence, b) optimized stratification sequence.

From a first analysis it was found that the thickness in the intersection area was less than $6 \mathrm{~mm}$, that was the expected thickness; in fact, it was equal to $4.3 \mathrm{~mm}$. Consequently, by calculating the difference between the nominal thickness, that is the desired one, and the obtained thickness, it was possible to determine the quantity of material necessary to get to the nominal thickness. This difference was equal to $1.7 \mathrm{~mm}$. In more details, the after cure thickness of a single layer of prepreg was determined by dividing the obtained thickness by the number of layers, that in the intersection zone was equal to 60; in such manner, a layer thickness of $0.072 \mathrm{~mm}$ was determined. Then, the number of missing layers in the intersection zone was calculated by dividing the difference previously determined by the layer thickness; as a result, it was found that 24 tape layers had to be added to the stratification to obtain the desired thickness of $6 \mathrm{~mm}$, that means 8 layers for each rib. Indeed, the single rib thickness was correct, while only the thickness in the intersection point was not as desired, so the correct solution consisted in redesigning the mould by varying the depth of the grooves in this area.

Before performing this design change on the mould, a simple modification was made to the groove intersection point, in such a way as to preliminarily verify whether the optimization strategy was correct. Therefore, another test was made by modifying the depth of intersection points by inserting a Teflon ${ }^{\circledR}$ sheet with a thickness of $1.7 \mathrm{~mm}$, as visible in Fig. 10 , and laying down 20 layers of prepreg, as stated in the paragraph "Design of tape stratification plan".

Another batch of 5 structures was manufactured and tested to verify the effectiveness of the preliminary optimization strategy. At the end of the cure process, the parts were visually inspected to understand whether the problem found on the head and base circumferences had been solved. As visible in Fig. 11, the bad stratification in the intersection points of the abovementioned circumferences disappeared, since the void spaces between fibre bundles were absent. Moreover, the thickness measurement confirmed a rib thickness of about $4.3 \mathrm{~mm}$, as expected. Calcination tests were carried out on these structures too, according to the strategy presented in the previous section. From the test results, reported in Table 6, it can be noted that the compaction level is satisfactory both in the intersection nodes and in the ribs (between two intersection nodes), since the fibre content was high while the void content was low, denoting a high quality level of the material and, consequently, a structural strength in line with expectations. However, the table show that the compaction level of the transition zone (specimen 6) was not as expected, since a too high void content, more than $5 \%$ that is the 
common threshold in the aeronautic field, coupled to undesired resin and fibre content, was found. It was also noted that near these points, immediately outside the Teflon $^{\circledR}$ sheet, there was a greater presence of resin, which formed a step as visible in Fig. 12.

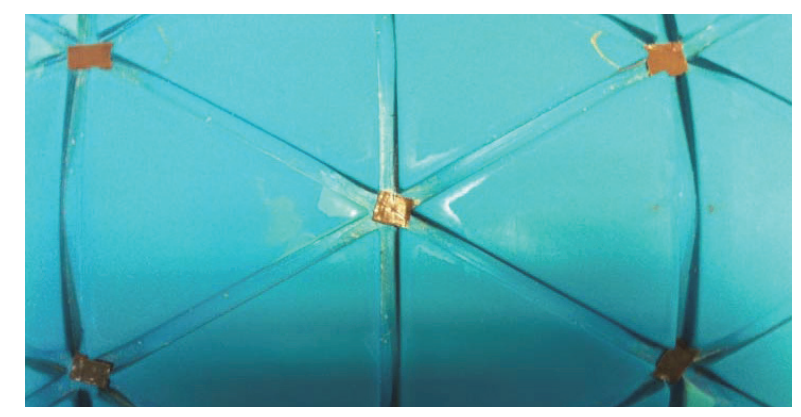

Figure 10: Depth modification by Teflon ${ }^{\circledR}$ sheets in the intersection points.

After this preliminary optimization step, the new experimental testing campaign confirmed the improvement of the structural characteristics of the produced parts, even if the material quality in the transition zones between the nodes and the single ribs was still scarce. Therefore, the application of more advanced design tools, as FEM simulation, was necessary to attain the required quality level of the structure.

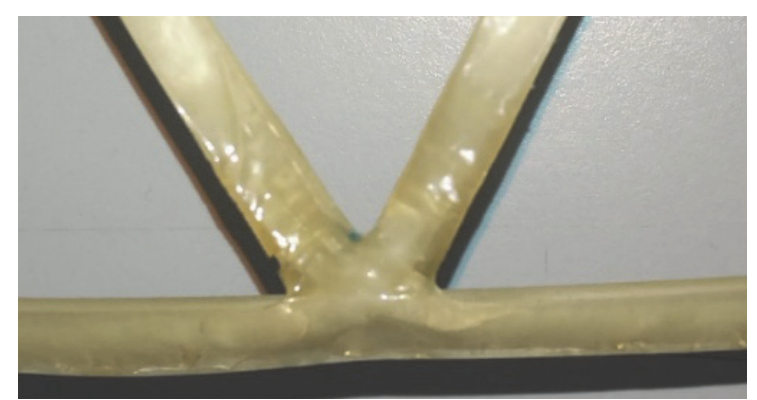

Figure 11: Defect absence in the circumferential head trajectory.

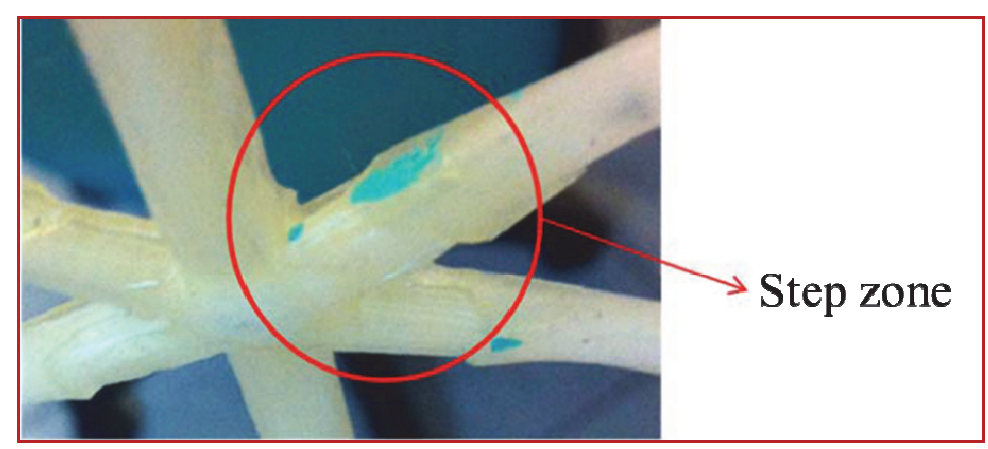

Figure 12: Detail that highlights areas with lower compaction.

\begin{tabular}{cccccccccc}
\hline \multirow{2}{*}{ Specimen } & \multicolumn{3}{c}{ Resin content $[\%]$} & \multicolumn{3}{c}{ Fibre content $[\%]$} & \multicolumn{3}{c}{ Void content $[\%]$} \\
& Average & St. Dev. & CoV & Average & St. Dev. & CoV & Average & St. Dev. & CoV \\
1 & 37.24 & 1.34 & $3.60 \%$ & 59.82 & 1.27 & $2.12 \%$ & 2.94 & 0.07 & $2.54 \%$ \\
2 & 38.47 & 1.59 & $4.13 \%$ & 58.76 & 1.35 & $2.30 \%$ & 2.77 & 0.06 & $2.33 \%$ \\
3 & 37.82 & 1.27 & $3.36 \%$ & 59.35 & 1.24 & $2.09 \%$ & 2.83 & 0.07 & $2.39 \%$ \\
4 & 38.53 & 1.65 & $4.28 \%$ & 58.37 & 1.43 & $2.45 \%$ & 3.10 & 0.07 & $2.15 \%$ \\
5 & 36.62 & 1.17 & $3.19 \%$ & 59.53 & 1.36 & $2.28 \%$ & 3.85 & 0.09 & $2.36 \%$ \\
6 & 47.35 & 2.37 & $5.01 \%$ & 38.64 & 2.45 & $6.34 \%$ & 14.01 & 0.69 & $4.92 \%$ \\
\hline
\end{tabular}

Table 6: Calcination test results after preliminary process design optimization. 


\section{CONCLUSIONS}

$\mathrm{I}$ $\mathrm{n}$ this paper a design methodology of a mould for manufacturing isogrid structure made of composite material was defined and evaluated through structural tests. In fact, some issue can arise during the production of this kind of parts, that are induced by a bad-designed process, in terms of parameters and tools. A particularly delicate area is located where the ribs intersect each other, because in that zones the material compaction is more uneven, dangerous residual tensions can arise and the non-uniformly distributed load caused by build-up can make cure induced deformation and damage initiation arise.

In this work, a methodology involving some solutions for the abovementioned issues is proposed. In particular, the mould grooves presented a variable depth to guarantee a correct compaction, since in the intersection points three times the material quantity was present than in the other parts. Another parameter to be taken into consideration was the tape stratification sequence, as it could influence the quality of the part.

In order to evaluate the suitability of the design methodology for the manufacturing of lattice structures, some structures of this type were produced and tested. In particular, the geometry dimensions were taken from a previous work; however, for the analysis carried out in this work, in order to highlight the rib properties, as the material compaction, only a sector equal to one fifth of the structure was manufactured and the lattice structure was produced without the skin.

For assessing the quality of a produced lattice structure, both qualitative and quantitative experimental tests were carried out. A visual inspection was suitable to highlight in qualitative manner the stratification induced defects and the rib compaction, while calcination tests and interlaminar shear strength tests were adopted to define in a quantitative manner the compaction degree and the quality of the ribs.

The first adopted stratification sequence was found not suitable since it induced some defects in the head and at the base of the structure. To design a new groove profile was deemed necessary as the rib compaction degree was found uneven. In this work a preliminary process design optimization was carried out in order to remove the presence of defects. A new stratification sequence was successfully introduced, in fact the void spaces in the head trajectories disappeared, and an acceptable compaction level was obtained in the intersection point. However, some issues were still present in the transition points, so making use of a more advanced design tool will be necessary.

\section{ACKNOWLEDGEMENTS}

7 his work was conducted under the R\&D project in implementation of Asse I - Research, Innovation and Strengthening of the productive basis of the POR FERS Lazio 2007-2013 (CO-RESEARCH). Special thanks to "Tecnologie Avanzate s.r.l." and Eng. R. Aricò for their support in this work.

\section{REFERENCES}

[1] Frulloni, E., Kenny, J.M., Conti, P. and Torre, L. (2007). Experimental study and finite element analysis of the elastic instability of composite lattice structures for aeronautic applications, Compos. Struct., 78(4), pp. 519-528.

DOI: 10.1016/j.compstruct.2005.11.013.

[2] Dawood, S.D.S., Inayatullah, O.B. and Samin, R.B. (2015). Computational study of the effect of using open isogrids on the natural frequencies of a small satellite structure, Acta Astronaut., 106, pp. 120-138.

DOI: $10.1016 /$ j.actaastro.2014.10.039.

[3] Totaro, G. (2015). Optimal design concepts for flat isogrid and anisogrid lattice panels longitudinally compressed, Compos. Struct., 129, pp. 101-110. DOI: 10.1016/j.compstruct.2015.03.067.

[4] Zheng, Q., Jiang, D., Huang, C., Shang, X. and Ju, S. (2015). Analysis of failure loads and optimal design of composite lattice cylinder under axial compression, Compos. Struct., 131, pp. 885-894. DOI: 10.1016/j.compstruct.2015.06.047.

[5] Totaro, G. (2012). Local buckling modelling of isogrid and anisogrid lattice cylindrical shells with triangular cells, Compos. Struct., 94, pp. 446-452. DOI: 10.1016/j.compstruct.2011.08.002.

[6] Totaro, G. (2013). Local buckling modelling of isogrid and anisogrid lattice cylindrical shells with hexagonal cells, Compos. Struct., 95, pp. 403-410. DOI: 10.1016/j.compstruct.2012.07.011.

[7] Totaro, G., De Nicola, F. and Caramuta, P. (2013). Local buckling modelling of anisogrid lattice structures with hexagonal cells: An experimental verification, Compos. Struct., 106, pp. 734-74. 
DOI: $10.1016 /$ j.compstruct.2012.07.011.

[8] Sun, F., Fan, H., Zhou, C., Fang, D. (2013). Equivalent analysis and failure prediction of quasi-isotropic composite sandwich cylinder with lattice core under uniaxial compression, Compos. Struct., 101, pp. 180-190. DOI: 10.1016/j.compstruct.2013.02.005.

[9] Vasiliev, V.V., Barynin, V.A., Razin, A.F. (2012). Anisogrid composite lattice structures - Development and aerospace applications, Compos. Struct., 94, pp. 1117-1127. DOI: 10.1016/j.compstruct.2011.10.023.

[10] Zheng, Q., Jiang, D., Huang, C., Shang, X., Ju, S. (2015). Analysis of failure loads and optimal design of composite lattice cylinder under axial compression, Compos. Struct., 131, pp. 885-894. DOI: 10.1016/j.compstruct.2015.06.047.

[11] Zheng, Q., Ju, S., Jiang, D. (2014). Anisotropic mechanical properties of diamond lattice composites structures, Compos. Struct., 109, pp. 23-30. DOI: 10.1016/j.compstruct.2013.10.053.

[12] Sui, Q., Fan, H., Lai, C. (2015). Failure analysis of 1D lattice truss composite structure in uniaxial compression, Compos. Sci. Technol., 118, pp. 207-216. DOI: 10.1016/j.compscitech.2015.09.003.

[13] Fan, H., Yang, L., Sun, F., Fang, D. (2013). Compression and bending performances of carbon fiber reinforced lattice-core sandwich composites, Compos. Part A Appl. Sci. Manuf., 52, pp. 118-125.

DOI: 10.1016/j.compositesa.2013.04.013.

[14] Wang, D., Abdalla, M.M. (2014). Global and local buckling analysis of grid-stiffened composite panels, Compos. Struct., 119, pp. 767-776. DOI: 10.1016/j.compstruct.2014.09.050.

[15] Bellini, C. and Sorrentino, L. (2018). Mould design for manufacturing of isogrid structures in composite material, Proc. Struct. Integr., 9, pp. 172-178. DOI: 10.1016/j.prostr.2018.06.027.

[16] Sorrentino, L., Bellini, C., Carrino, L., Leone, A., Mostarda, E., Tersigni, L. (2009). Cure process design to manufacture composite components with variable thickness by a closed die technology, 17th International Conference on Composite Materials, ICCM-17; Edinburgh; United Kingdom; Code 85394

[17] Young, W. (2013). Three-dimensional modeling of the advanced grid stiffened structures in the co-curing process, Compos. Part A Appl. Sci. Manuf, 46, pp. 19-25. DOI: 10.1016/j.compositesa.2012.10.013.

[18] Bellini, C., Sorrentino, L. (2018). Analysis of cure induced deformation of CFRP U-shaped laminates, Compos. Struct., 197, pp. 1-9. DOI: 10.1016/j.compstruct.2018.05.038.

[19] Kim, T.D. (2000). Fabrication and testing of composite isogrid stiffened cylinder, Compos. Struct., 49, pp. 21-25. DOI: 10.1016/S0263-8223(98)00124-X.

[20] Sorrentino, L., Marchetti, M., Bellini, C., Delfini, A., Albano, M. (2016). Design and manufacturing of an isogrid structure in composite material: Numerical and experimental results, Compos. Struct., 143, pp. 189-201. DOI: 10.1016/j.compstruct.2016.02.043.

[21] Sorrentino, L., Marchetti, M., Bellini, C., Delfini, A., Del Sette, F. (2017). Manufacture of high performance isogrid structure by Robotic Filament Winding, Compos. Struct., 164, pp. 43-50. DOI: 10.1016/j.compstruct.2016.12.061. 